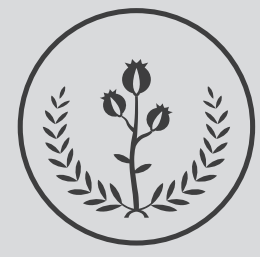

FUCS

\title{
VI Encuentro Nacional de Semilleros de Investigacion en Salud
}

\section{Sixth National Meeting of Health Research Incubators}

${ }^{a}$ Vicerrector de Investigaciones. Fundación Universitaria de Ciencias de la Salud-FUCS. Bogotá DC, Colombia.

(C) 2021 Fundación Universitaria de Ciencias de la Salud - FUCS. Este es un artículo Open Access bajo la licencia CC BY-NC-ND (http://creativecommons.org/licenses/by-nc-nd/4.0/).

\begin{abstract}
"Hacia la consolidación de una cultura de investigación en salud desde las nuevas generaciones"
\end{abstract}

El origen de la educación universitaria a partir de siete artes liberales reunidas en el Trívium (gramática, dialéctica y retórica) y el Quadrivium (aritmética, geometría, astronomía y música), marcan un cambio generacional irreversible en la edad media. El joven estudiante era formado en el uso del trívium como instrumento para el autoaprendizaje y después a través del quadrivium profundizaba en el conocimiento de las ciencias y las artes. Bajo este modelo se formaron científicos notables como Nicolás Copérnico, Isaac Newton, Marie Curie, Henri Poincare, Iván Pávlov e Iliá Méchnikov, entre muchos otros. Un elemento común en el proceso educativo de estos investigadores fue la formación y guía recibida en un momento determinante de sus vidas por su mentor, un profesional con experiencia y alta formación, pero ante todo un consejero, capaz de motivar y potenciar con disciplina y constancia las habilidades innatas del joven estudiante por el conocimiento, materializando así sus sueños en un proyecto de vida con vocación de servicio social.

Este principio sigue vigente en el tiempo y es la esencia de lo que conocemos hoy como "semilleros de investigación", un escenario extracurricular en el cual el docente y los estudiantes bajo el ejercicio de la investigación, comparten experiencias de reflexión y critica al conocimiento vigente en un área de la ciencia. En el caso de las áreas de la salud, la problemática evidenciada a través del ejercicio asistencial cotidiano, constituye el mejor substrato para el surgimiento de interrogantes y también el reto que inspira la generación y ejecución de procesos y proyectos de investigación, cuyos productos pueden directa o indirectamente constituir soluciones a estos interrogantes con potencial aplicación en el paciente y la comunidad generando un impacto social.

\section{INFORMACIÓN DEL ARTÍCULO}

Historia del artículo:

Fecha recibido: agosto 20 de 2021

Fecha aceptado: septiembre 6 de 2021
Autor para correspondencia.

Dr. Arley Gómez López agomez@fucsalud.edu.co
DOI

10.31260/RepertMedCir.01217372.1283 
Además de los beneficios académicos y científicos antes mencionados, durante la participación en los semilleros los estudiantes desarrollan múltiples habilidades que consolidan el interés por su área de estudio, adquieren destrezas en el manejo y análisis de bases de datos, fortalecen su capacidad de trabajo en equipo y en redes interdisciplinarias, fortalecen sus habilidades de comunicación y apropiación social del conocimiento, mediante la redacción de manuscritos científicos y la exposición de los resultados de investigación en eventos nacionales e internacionales.

Comprometida con la formación en investigación en salud de las nuevas generaciones de profesionales, la Fundación Universitaria de Ciencias de la Salud - FUCS ha incorporado dentro de la política de investigación el proyecto educativo institucional y sus estrategias de fomento a la investigación, el apoyo continuo a los semilleros de investigación. El testimonio de ello es la creación y apoyo continuo al "Encuentro Nacional de Semilleros de Investigación en Salud - ENSI" un escenario creado hace doce años, el cual se ha consolidado como el ambiente propicio para la participación e interacción de jóvenes semillas de diversas áreas de la salud provenientes de distintas regiones e instituciones de educación superior nacional, quienes durante 3 días comparten experiencias con reconocidos investigadores nacionales e internacionales y llevan a cabo la difusión de resultados de los proyectos de investigación.

Es importante destacar que ante las limitaciones generadas por la pandemia del COVID19, en esta ocasión el "VI Encuentro Nacional de Semilleros de Investigación en Salud" se llevó a cabo de forma virtual. Agradecemos a todos los jóvenes la inmensa acogida a nuestra convocatoria, reflejada en la recepción de 765 trabajos de investigación de los cuales una vez revisados los requisitos establecidos se seleccionaron 735 para evaluación por pares académicos de reconocida experiencia. De acuerdo con los resultados finales fueron escogidos 241 trabajos para presentación oral, 199 para póster oral y 80 en modalidad póster electrónico. Sea esta la oportunidad para felicitar a todos los jóvenes participantes y renovarles nuestra invitación para que asistan a las distintas conferencias y presentaciones durante los tres días de duración del evento.

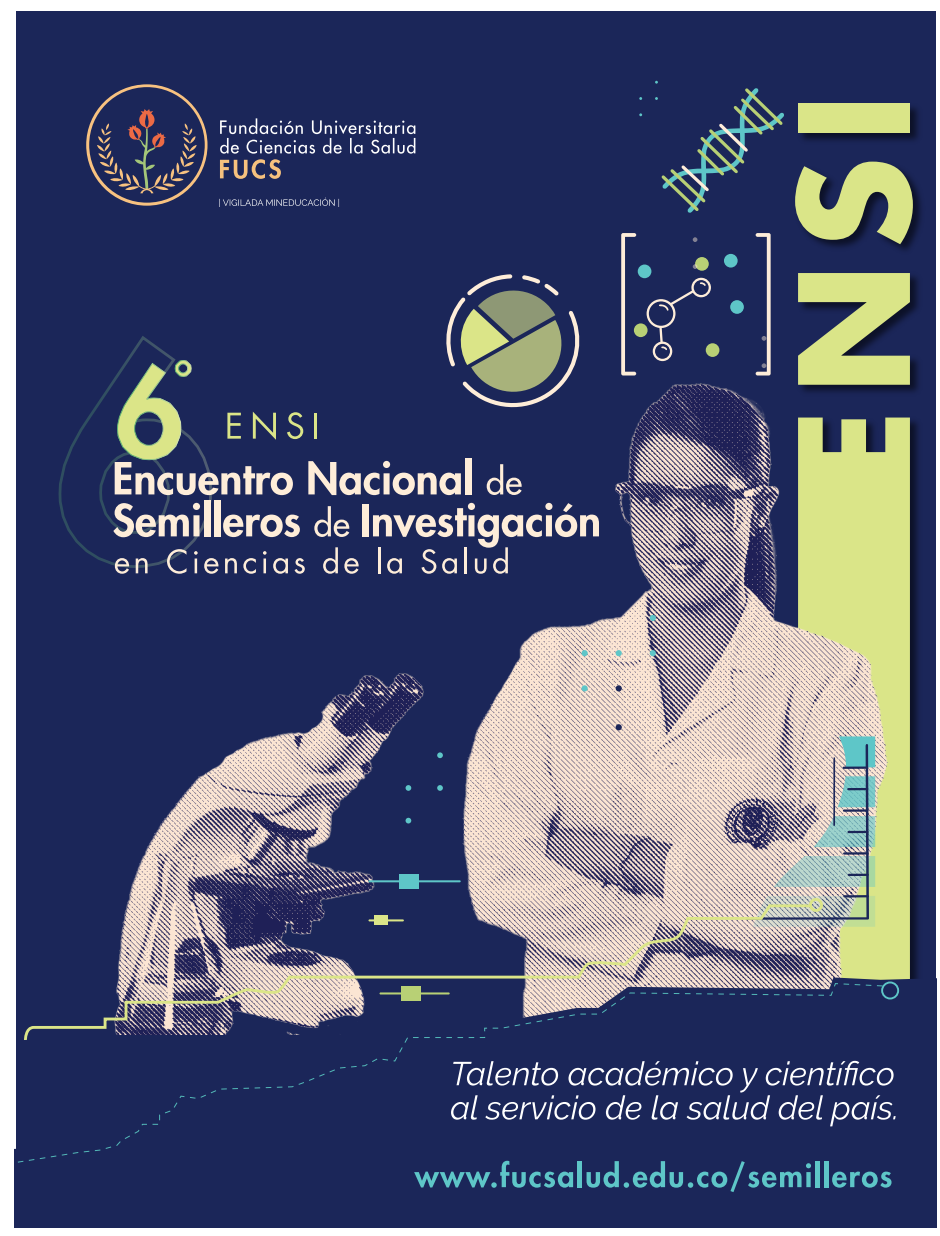

Figura 1. Pauta "VI Encuentro Nacional de Semilleros de Investigacion en Salud". 